\title{
DRY ICE - USEFUL MATERIAL IN WELDING PERFORMANCE
}

\author{
S.N. ZHIZNYAKOV \\ Belarusian National Technical University \\ 65 Nezavisimosti Ave., 220013, Minsk, Belarus. E-mail: zhiznyackov@yandex.by
}

\begin{abstract}
The problem of modification of welding methods applied in industry, including application of new welding consumables, is challenging. It is shown that as an efficient welding consumable in arc methods of welding the dry ice (solid carbon dioxide) can be applied, which is facilitated by its unique properties, namely possibility of sublimation with formation of great amount of gases and very low temperature. Dry ice staying in welding zone forms a reliable protective gas environment of specific composition, which predetermines also a favorable arrangement of forces acting on the drop of electrode metal. In welding a stable mild arcing without excessive spattering with a good weld formation is observed. The ice sharply decreases residual welding deformations in welding of thin-sheet metal. In principle, the new arc welding method using consumable electrode, i.e. welding under dry ice, was offered, which is performed applying conventional welding equipment. Welding under dry ice can be used during manufacture, erection and repair of steel structures. The experiments showed that dry ice as an additional welding consumable is applicable in manual arc welding using covered electrodes, welding using flux-cored wire, in shielding gas and also during performance of surfacing works. 4 Ref., 4 Figures.
\end{abstract}

$\boldsymbol{K} \boldsymbol{e} \boldsymbol{y} \boldsymbol{w} \boldsymbol{o} \boldsymbol{r} \boldsymbol{d} \boldsymbol{s}:$ arc welding, dry ice, complete gas protection, stable process, minimum deformations, application

Welding consumables, i.e. covered metallic electrodes, shielding gases, solid wire and flux-cored wire, fluxes, non-consumable electrodes, directly participate in the process of arc welding, performing the most important technological and metallurgical functions providing possibility of efficient fulfillment of welding works and producing quality welded structures [1]. The given list of welding consumables (it was shown by the investigations performed in the Belarusian National Technical University) can be supplemented by the dry ice (solid carbon dioxide) characterized with clearly distinct specific properties quite useful for welding process.

These properties are:

- very low temperature of ice, not exceeding $-78.5^{\circ} \mathrm{C}$. At forced interaction of ice with metal the latter cools down intensively. The layer of ice is capable to be very long time on the metal surface under the normal conditions preserving its structure and physical properties. The cold efficiency of dry ice several times exceeds that of water ice;

- capacity of dry ice to sublimation, i.e. transition from solid crystal state immediately to the gaseous one omitting the liquid phase with absorption of heat in the amount of about $590 \mathrm{~kJ} / \mathrm{kg}$ at normal pressure and temperature

(C) S.N. ZHIZNYAKOV, 2014 of $-78.5{ }^{\circ} \mathrm{C}$. Here about 0.81 of carbon gas is formed of $1 \mathrm{~g}$ of ice at its complete evaporation;

- dry ice is characterized by a very high purity. According to GOST 12162-77 the mass fraction of carbon dioxide in it amounts to $99.96-99.98 \%$, practical content of carbon dioxide in the yield product amounts to $99.998 \%$ at negligible humidity content.

Dry ice is convenient for realization. It is transported and stored in the thermal containers of different capacity from 2 to $250 \mathrm{~kg}$ and more. Depending on design peculiarities of container and ambient temperature the dry ice does not loose its characteristics within several days. The losses during storage usually amount to $2-10 \%$ of mass of ice per day. The ice is not toxic, not scarce, it is widely used in industry, agriculture, medicine, etc. The ice is usually supplied in the form of blocks and granules of different size. The density of dry ice is $1560 \mathrm{~kg} / \mathrm{m}^{3}$.

High temperature non-uniform heating with next cooling of elements being joined in arc welding causes the occurrence of residual deformations in them hindering the production of welded structures and deteriorating their quality. One of the most rational technical solutions directed to reduction of deformations is local cooling of metal in the welding zone. It narrows the sizes of areas of welded joint, heated in the welding process to the possible minimum, to the temperatures when compression forces arise exceeding the yield strength of metal being welded (for the steels, mainly, the zones heated to the temperatures of 


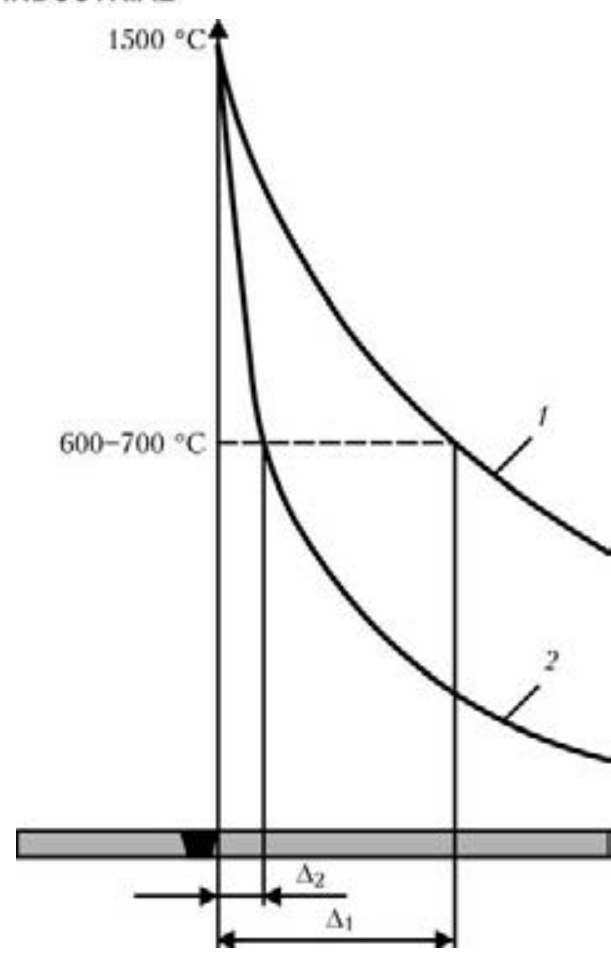

Figure 1. Scheme of distribution of maximum temperatures of heating of metal (steel) in welding in carbon gas using conventional method (1) and under layer of dry ice (2): $\Delta_{1}$ and $\Delta_{2}-$ width of areas of metal heated above $600-700{ }^{\circ} \mathrm{C}$ in welding without and with dry ice, respectively

more than $600-700{ }^{\circ} \mathrm{C}$.) It is the origination of such critical areas that predetermines initiation with the following propagation of plastic deformations and producing of welded joints and structures with residual welding deformations and stresses.

The applied methods for heat removal from the metal heated during welding (water-cooled copper backing and shoes, massive clamping devices, liquid coolers in the form of directed solid and sprayed jets) are not capable to render the noticeable local effect on critical high-temperature zones of metal, especially those being near the weld pool. It was found that this function on spot contact heat removal from the metal heated in welding can be successfully performed by dry ice.

Experimental and theoretical investigations [2] allowed authors to develop main guidelines of universal technology of argon arc welding of thin-sheet high-alloyed steel of austenite class of the type 18-8 applying solid carbon dioxide for the forced cooling of high-temperature area of elements being welded, allowing several times decreasing the residual deformations as compared to welding without cooling. In welding of metal of $1 \mathrm{~mm}$ thickness the rational area of contact cooling in high-temperature zones at the certain distance from the boundary of weld pool amounted to $60-90 \mathrm{~mm}^{2}$ at length of not less than $6 \mathrm{~mm}$. The development of welding technology was carried out using the developed methods [2] of numerical modeling of temperatures, stresses and deformations in different areas of plates being welded considering the specifics of behavior of austenite steel and peculiarities of low-temperature cooler, i.e. dry ice.

In welding of steel plates in carbon gas the unique possibility of cooling of metal using dry ice was revealed, which is heated directly ahead the arc along the frontal boundary of weld pool. It occurs in welding under the layer of dry ice. Layer of ice being at the surface of plates almost does not react with the metal before welding. However at entering the direct counteraction with the metal, heated in welding to higher temperatures up to melting, the active sublimation of ice with absorption of great amount of heat occurs. Dry ice, which did not manage to evaporate as a result of sublimation, comes into contact with weld pool, where, after reaction with liquid metal, it vanishes immediately, i.e. weld pool appears to be bordered by low-temperature solid dry ice. Interaction of metal adjacent to weld pool with dry ice reduces sizes of high-temperature areas, where active propagation of plastic deformations is possible (Figure 1).

Thus, in welding of thin-sheet metal using the technology under the layer of dry ice providing additional cooling of cooled weld metal and HAZ on the high-temperature areas using ice cooling, the welded joints and structures without any residual deformations can be produced. Application of dry ice as an intensive cooler is possible in manual covered electrode arc welding and other fusion methods. The noticeable increase of rate of cooling of the thin-sheet metal in this case affects its structure and properties (in this article this issue is not considered). It is naturally that welding using dry ice can be applied only for metal not prone to formation of brittle hardening structures, cracks and other defects during sharp cooling.

The experiments on welding under the layer of dry ice allowed revealing the important phenomenon for the further investigations, namely the amount of gases formed in the welding zone is sufficiently enough for its reliable protection from the air. Moreover, the composition of gaseous phase represents not a pure carbon gas but its mixture with carbon oxide (Figure 2). The formation of gaseous phase of this composition can be explained in the following way.

Carbon gas is formed as a result of sublimation of a part of dry ice directly adjacent to the surface 
of metal heated in welding. With increase of temperature of metal the rate of evaporation of ice grows by many times and reaches maximum at the temperatures close to the temperature of its melting. As the major mass of ice does not manage to evaporate, its bigger part «creeps down» to the neighboring high-temperature area of weld pool in the process of welding, where it comes into direct contact interaction with the molten metal being in the constant movement. In the limited space almost instant sublimation of ice with evolution of enormous amount of carbon gas occurs, resulting in sharp growth of its concentration and partial pressure in the area of contact of liquid and gaseous phases. It instantly causes high-rate and full-scale running of reaction $\mathrm{Fe}_{1}+$ $+\mathrm{CO}_{2}=\mathrm{FeO}_{1}+\mathrm{CO}$. Carbon oxide formed in a great amount, as well as remnants of carbon gas which did not entered the reaction, form together with carbon gas the sublimated dry ice, being in contact with hot surface of solid metal, a protective gaseous phase of welding zone. The carried out investigations give grounds to suppose that content of carbon oxide as a product of the considered reaction in the arc zone in welding of steel under the layer of dry ice can reach $60-70 \%$. At interaction with air the carbon oxide reacts with oxygen transforming into carbon gas.

The arc welding process in mixture of carbon with carbon oxide differs considerably (and it was confirmed during experimental investigations) from the welding process in carbon gas only. In welding in mixture the stable mild arcing without excessive spattering of molten metal is observed, coarse-rippled surface of weld is absent. The process is similar to welding in the mixture of argon with carbon gas. Stable arcing and good weld formation and its outer appearance are typical of welding under the protection of carbon oxide only [3].

Change in nature of arcing and type of electrode metal drop transfer in welding in the mixture of carbon oxide with carbon gas is connected with low concentration of carbon gas in the mixture. The presence of great amount of carbon oxide in the arc gap hinders the dissociation of carbon gas, resulting in intensive cooling of arc plasma and constriction of its active spots, and as a result the extremely unfavorable arrangement of forces affecting the drop of electrode metal, in the first turn, the force of pinch-effect, reactive force of pressure of vapors of metal and force of pressure of arc plasma flows. High concentration of carbon oxide in gaseous phase delays the oxidation processes running in the welding zone to a certain degree.

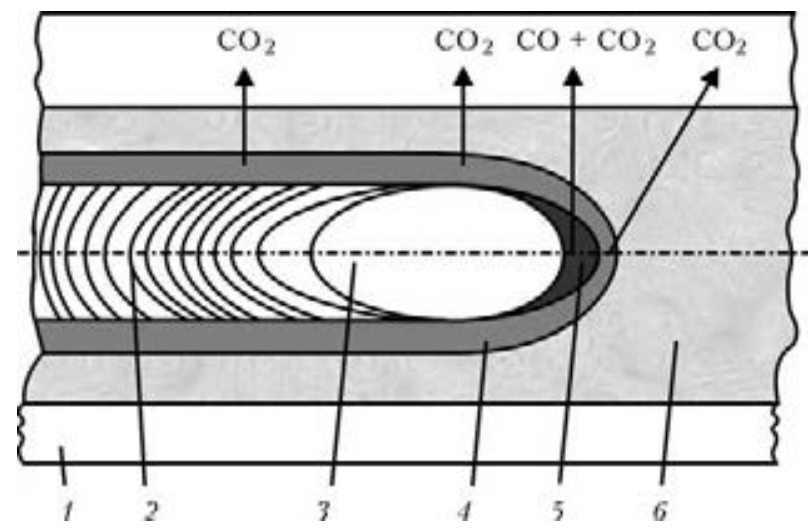

Figure 2. Scheme of formation of protective gaseous phase in arc welding under the dry ice layer: 1 - base metal; 2 - weld; 3 - weld pool; 4 - areas of contact of dry ice layer with surface of metal heated up to high temperatures in welding; 5 - zone of interaction between the metal of weld pool and dry ice; 6 - layer of dry ice

Basing on the results of investigations carried out in co-authorship with colleagues from the Belarus National Technical University, the principally new method of arc welding using consumable electrode, namely welding under dry ice [4], was developed. Mechanized and automatic consumable electrode arc welding under dry ice is carried out without outer gas and slag (flux) protection (Figure 3). The basic welding consumables are solid carbon dioxide and wire containing deoxidizers.

Deposition of beads and welding of butt and T-joints of low-carbon and low-alloyed steels of average thickness, applying solid carbon dioxide according to GOST 12162-77 and wires of grade Sv-08G2S according to GOST 2246-70, showed stable arcing with minimum spattering of molten metal, good formation and appearance of a weld, absence of pores, solid inclusions and other inadmissible defects in welded joints (Figure 4). Welds are characterized by high mechanical properties: tensile strength $\sigma_{\mathrm{t}}=580-620 \mathrm{MPa}$, elongation $\delta_{5}=23-27 \%$, impact toughness at normal temperature $K C U=135-160 \mathrm{~J} / \mathrm{cm}^{2}$. In welding

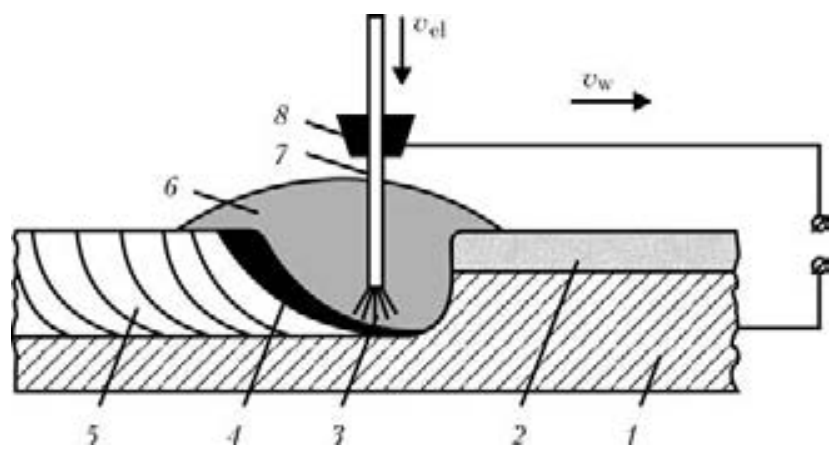

Figure 3. Scheme of arc welding under the dry ice layer: 1 - base metal; 2 - dry ice layer; 3 - arc; 4 - weld pool; 5 - weld; 6 - gas protection of welding zone; 7 electrode welding wire; 8 - current collecting tip (current conductor) 

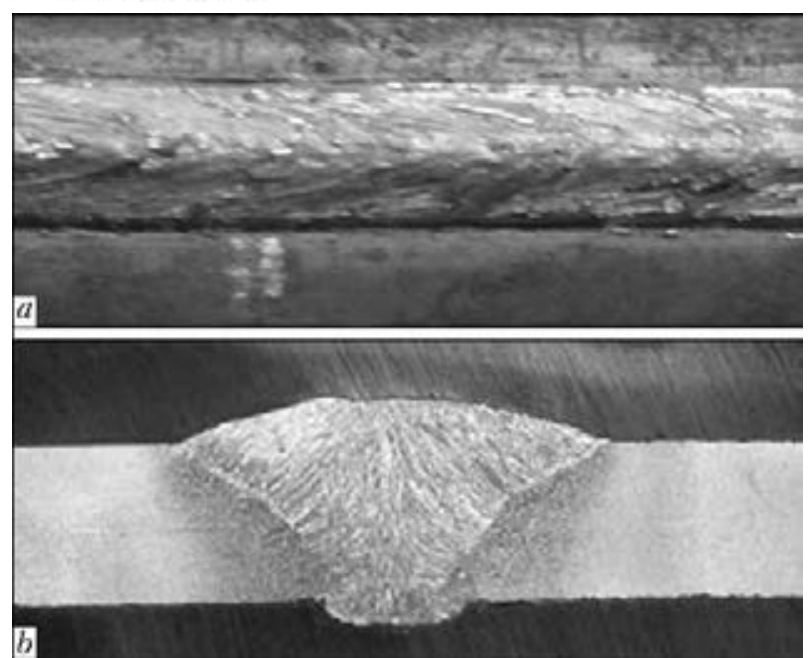

Figure 4. Appearance $(a)$ and macrosection $(b)$ of welded joint in mechanized welding of low-alloyed steel $6 \mathrm{~mm}$ thick under the dry ice

of thin-sheet steel the decrease of residual welding deformations by 5-10 times was observed.

The techniques and technology of welding under dry ice are differed form welding in carbon gas, which is predetermined by the peculiarities of formation of protective gaseous phase in arc zone and specifics of welding process performance. The noticeable effect of force of pressure of carbon gas, forming at explosive high-temperature sublimation of dry ice at the surface of liquid metal, on weld pool should be also considered. Welding of butt, fillet and spot welds can be performed using dry ice in the form of briquettes, plates and granules of different sizes produced also in crushing and refining of initial materials. Ice prepared for welding is laid out preliminary at the whole length of welded joint by the layer of a definite thickness and width or introduced «beneath the arc». In both cases the scheme of welding can be applied, at which dry ice is additionally supplied behind the arc on preset areas of cooled weld and/or HAZ metal. The similar scheme of process represents interest for one pass deformation-free welding of thin-sheet metal and multipass welding of metal of average and large thickness, when layer-by-layer cooling of weld is necessary, for example, in welding of austenite steel.
Mechanized and automatic welding under dry ice is performed using conventional equipment. Here simplified designs of welding torches and flexible hoses are applied, as far as there is no longer need in supply of shielding gas to the welding zone through the torch. The cylinders with shielding gas and gas equipment are replaced by a simple thermostat with dry ice.

\section{Conclusions}

1. Dry ice is capable to participate directly in the arc welding process, performing important technological and metallurgical functions and providing stable running of the process of producing the quality welded joints itself. It gives grounds to consider it as a full-fledged welding consumable suitable for successful application in welding production.

2. The developed principally new method of welding using consumable electroand - Ice Metal Arc Welding - not requiring the gas and slag protection and performed applying conventional welding equipment, can be used in manufacture, repair and erection of steel structures and constructions.

3. Dry ice as a welding consumable is applicable in manual covered-electrode arc welding and other fusion methods, and also during performance of surfacing works and cutting of metals.

1. Zhiznyakov, S.N. (2013) Proper selection and preparation of welding consumables as a base of efficient welding production works. Svarshchik v Belorussii, 1, 32-38.

2. Panteleenko, F.I., Zhiznyakov, S.N., Heidari Monfared, A. (2013) Minimization of deformations in argon arc welding of sheet austenitic steel by local cooling of high-temperature field. In: Advanced materials and technologies. Ed. by V.V. Klubovich. Vitebsk: UO VGTU, 172-187.

3. Novozhilov, N.M. (1979) Principles of metallurgy of gas-shielded arc welding. Moscow: Mashinostroenie.

4. Zhiznyakov, S.N., Panteleenko, F.I., Viktorovsky, D.I. et al. (2013) Arc and ice. New method of consumable electrode arc welding. In: Powder metallurgy: surface engineering, new powder composite materials. Welding: Proc. of 8th Int. Symp. (Minsk, 10-12 April, 2013), Pt 2. Minsk: Bel. Navuka, 347-349.

Received 21.12.2013 